Jameson, J. E. \& Emberley, N. W. (1956). J. gen. Microbiol. 15, 198-204

\title{
A Substitute for Bile Salts in Culture Media
}

\author{
By J. E. JAMESON AND N. W. EMBERLEY
}

Public Health Laboratory, Brighton

SUMMARY: Teepol, a modern anionic detergent, has been investigated and used in culture media for organisms of the coli-typhoid group, in substitution for bile salts. Media containing $0.1 \%$ Teepol and an indicator of the sulphonphthalein group have been found to possess advantages over MacConkey's medium. While bile salts as marketed are costly and variable in their bacteriological properties, Teepol is cheap and reliable.

MacConkey (1908) described a culture medium which still has a wide field of use. This medium incorporates an intestinal detergent, sodium taurocholate, which confers selectivity and suppresses the swarming of Proteus. Lominski \& Lendrum (1942) showed that swarming is inhibited by surface active agents, particularly straight chain alkyl sulphates which have a peak of antiswarming activity when the molecular chain has 12 carbon atoms.

Several household detergents are known to be bacteriostatic to Gram-positive organisms as well as being surface active, and the possibility of finding one which could replace sodium taurocholate logically presented itself.

\section{METHODS}

The selectivity factor of detergents was determined as follows: Duplicate doubling dilutions of known strength in distilled water were prepared. To $0.5 \mathrm{ml}$. of each dilution of detergent in a sterile tube was added an equal volume of double strength Lemco broth. To each tube of one series was added $0.02 \mathrm{ml}$. of a 1/2500 dilution in broth of a $6 \mathrm{hr}$. broth culture of the standard Oxford staphylococcus. A similar inoculum of Escherichia coli $\mathbf{0 5 5}$ was added to the second series. All tubes were examined for turbidity after $24 \mathrm{hr}$. at $37^{\circ}$; the lowest concentration of detergent showing absence of turbidity was recorded.

The anti-swarming factor was determined by pouring plates of doubling dilutions of the detergents in nutrient agar. After drying, each plate was touched at one point with an inoculum of a swarming strain of Proteus, and incubated at $37^{\circ}$ for $18 \mathrm{hr}$. The lowest concentration which suppressed swarming was recorded.

We first selected two detergents in laboratory use, Cetrimide (Cetavlon, I.C.I.) for its known bacteriostatic properties, and Teepol (Shell) partly because previous unpublished work had suggested that this detergent might well have a use in culture media, and partly because we knew that it contained alkyl sulphates. The selectivity and anti-swarming factors of these agents were ascertained and compared with those of the following bile salts: sodium taurocholate, sodium tauro-glycocholate and sodium deoxycholate (Table 1). Escherichia coli 055 grew freely in the highest concentrations of 
sodium taurocholate and of sodium deoxycholate that were technically convenient to prepare. We have therefore expressed the selectivity and anti-swarming factors of these salts as 'greater than' values. As it would not be practicable to use bile salts in higher concentrations than those at which we tested them, for practical purposes the 'greater than' symbols in the table can be ignored. The results shown in Table 1 indicated that Teepol is potentially a more suitable ingredient for MacConkey's medium than either sodium taurocholate or sodium tauro-glycocholate. Cetrimide also showed potentialities in this direction, but we discarded it in favour of Teepol on account of the relatively low value of the anti-swarming factor of Cetrimide, namely 10.

Before carrying out further tests on Teepol we wished to be satisfied that it is of constant chemical composition. In correspondence with the makers (Shell Chemicals Ltd., Norman House, 105/109 Strand, London, W.C. 2), we were supplied with the following information; the active organic detergent in Teepol consists of sodium or potassium salts of alkyl sulphates, the alkyl radicles ranging from 8 to $\mathbf{1 8}$ carbon atom chains. These alkyl groups are present in approximately equal proportions, so that the proportion of 11,12 and 13 carbon atom chains would be three-elevenths of the total. The method of manufacture is such that the variation from this figure would be very small and probably not more than $\pm 1 \%$. The other constituents of Teepol as marketed are sodium and potassium sulphates up to $4 \%$ by weight, and small residues of unsulphated organic matter which do not exceed $1 \%$ by weight.

At our request the makers sent us ten representative batches of Teepol and a sample of the olefines from which it is manufactured, which are liable to be present in the unsulphated organic matter referred to above.

Eight batches of Teepol sent by the makers and two batches in use in the laboratory were tested. The selectivity and anti-swarming factors of each batch were ascertained. These factors were identical with those given in Table 1 in every case, and the end-points obtained in determining these ratios were all the same.

Table 1. Assay of detergents

\begin{tabular}{|c|c|c|c|c|c|}
\hline Detergent & $\begin{array}{c}\text { Escherichia } \\
\text { coli } \\
\text { minimum } \\
\text { inhibitory } \\
\text { concentration } \\
(A)\end{array}$ & $\begin{array}{l}\text { Oxford staphylo- } \\
\text { coccus } \\
\text { minimum } \\
\text { inhibitory } \\
\text { concentration } \\
(B)\end{array}$ & $\begin{array}{c}\text { Minimum } \\
\text { anti- } \\
\text { swarming } \\
\text { concentration } \\
(C)\end{array}$ & $\begin{array}{c}\begin{array}{c}\text { Selectivity } \\
\text { factor }\end{array} \\
\left(\frac{1}{B} \div \frac{1}{A}\right)\end{array}$ & $\begin{array}{l}\text { Anti- } \\
\text { swarming } \\
\text { factor } \\
\left(\frac{1}{C} \div \frac{1}{A}\right)\end{array}$ \\
\hline $\begin{array}{l}\text { Sodium } \\
\text { taurocholate }\end{array}$ & $\frac{>1}{12}$ & $\frac{1}{50}$ & $\frac{1}{400}$ & $>4$ & $>33$ \\
\hline $\begin{array}{l}\text { Sodium tauro- } \\
\text { glycocholate }\end{array}$ & $\frac{1}{12}$ & $\frac{1}{400}$ & $\frac{1}{400}$ & $\mathbf{3 3}$ & 33 \\
\hline $\begin{array}{l}\text { Sodium } \\
\text { deoxycholate }\end{array}$ & $\frac{>1}{12}$ & $\frac{1}{3200}$ & $\frac{1}{800}$ & $>267$ & $>67$ \\
\hline Cetrimide & $\frac{1}{3200}$ & $\frac{1}{2,560,000}$ & $\frac{1}{32,000}$ & 800 & 10 \\
\hline Teepol & $\frac{1}{3}$ & $\frac{1}{1600}$ & $\frac{1}{3200}$ & 533 & 1067 \\
\hline
\end{tabular}


To ascertain whether the sample of olefines had any bacteriologically undesirable property, we attempted to dissolve this material in nutrient broth at $37^{\circ}$. The olefine had an extremely low solubility in broth and a 'saturated solution' of it in nutrient broth at $37^{\circ}$ freely supported growth of Escherichia coli $\mathrm{O55}$ and of the Oxford staphylococcus.

\section{Teepol media}

We decided to use Teepol in a concentration of $0 \cdot 1 \%$ in media. The results of our tests had indicated that Teepol might safely be used in a much higher concentration than this, but by selecting a concentration near to the minimum effective level we gained the advantage of obtaining a greater dilution of such impurities as might be present. A MacConkey agar was therefore made up containing $0.1 \%$ Teepol in substitution of bile salt. This medium tended to precipitate the neutral red dye. Attention was then directed to the sulphonphthalein group of indicators. After trial we chose bromthymol blue for solid media. Colonies of Escherichia coli are large and opaque, and with this indicator give a characteristic cream colour. Colonies of Salmonella and Shigella are less opaque and are pale green except in the vicinity of lactose-fermenting colonies when they show up as a deeper shade of yellow against the creamy colonies of $\boldsymbol{E}$, coli. Bromcresol purple was found to give a more clear-cut result in liquid media since with this indicator the colour change does not begin to occur until the $\mathrm{pH}$ has fallen to $6 \cdot 8$.

The composition of the media used in our laboratory trials was as follows:

Teepol agar
$2 \%$ Eupeptone No. 2
(Allen and Hanburys)
$1 \%$ Lactose
$0.5 \%$ Sodium chloride
$0.1 \%$ Teepol
$0.005 \%$ Bromthymol blue

\begin{tabular}{cc}
\multicolumn{1}{c}{ Lemco agar } & \multicolumn{1}{c}{ MacConkey agar } \\
$1 \%$ Eupeptone No. 2 & $2 \%$ Eupeptone No. 2 \\
(Allen and Hanburys) & (Allen and Hanburys) \\
$1 \%$ Lab. Lemco & $1 \%$ Lactose \\
$0.5 \%$ Sodium chloride & $\mathbf{0 . 5} \%$ Sodium chloride \\
& $\mathbf{0 . 5} \%$ Sodium taurocholate \\
& $\mathbf{0 . 0 0 3} \%$ Neutral red
\end{tabular}

All media were solidified with $0.9 \%$ New Zealand (Davis) agar, and the pH value adjusted to $7 \cdot 6$. The composition of the fluid media was identical with that of the respective solid media except for the exclusion of agar from the former, the use of $0.005 \%$ bromcresol purple in both fluid media, and the substitution of sodium tauro-glycocholate for sodium taurocholate in MacConkey broth. The $\mathrm{pH}$ value of the fluid media was adjusted to 7.5. Since completion of the trials we have preferred the use of bromcresol purple at $0.001 \%$.

\section{RESULTS}

Teepol agar. In order to show that Teepol agar is as favourable to intestinal pathogens as MacConkey agar, plate counts were made by the technique of Miles \& Misra (1938) using six tenfold dilutions on each of three plates. The counts were put up in quadruplicate using the following media: Lemco agar, MacConkey agar containing $\mathbf{0 . 5} \%$ sodium taurocholate (taurocholate MacConkey), MacConkey agar containing $\mathbf{0 . 5} \%$ sodium tauro-glycocholate (tauro- 
glycocholate MacConkey), and Teepol agar. Counts were made on broth cultures of ten intestinal pathogens and of two non-pathogens. The results of these counts, expressed in millions, are set out in Table 2 , from which it will be seen that in eleven instances out of twelve the counts on Teepol agar were higher than on taurocholate MacConkey agar. The counts on Lemco agar, tauro-glycocholate MacConkey and Teepol agar did not differ from each other significantly.

Table 2. Plate counts made from 12 organisms on Teepol agar, Lemco agar and on two bile salt media

Counts are expressed in millions of organisms $/ \mathrm{ml}$.

\begin{tabular}{|c|c|c|c|c|}
\hline Organisms & $\begin{array}{c}\text { Lemco } \\
\text { agar }\end{array}$ & $\begin{array}{l}\text { Taurocholate } \\
\text { MacConkey } \\
\text { agar }\end{array}$ & $\begin{array}{c}\text { Tauro- } \\
\text { glycocholate } \\
\text { MacConkey } \\
\text { agar }\end{array}$ & $\begin{array}{c}\text { Teepol } \\
\text { agar }\end{array}$ \\
\hline Salmonella typhi & 300 & 265 & 340 & 320 \\
\hline S. paratyphi-B & 335 & 305 & 350 & $\mathbf{3 5 0}$ \\
\hline S. typhimurium & 320 & $\mathbf{3 5 0}$ & 315 & 355 \\
\hline Shigella sonnei & 320 & 235 & 355 & 360 \\
\hline $\begin{array}{l}\text { S. flexneri type } 2 \\
\text { Escherichia coli }\end{array}$ & 250 & 255 & 230 & 235 \\
\hline 026 & 445 & 345 & 395 & 380 \\
\hline 055 & 425 & 370 & 435 & 400 \\
\hline 0111 & 290 & 250 & 305 & 305 \\
\hline 0119 & 350 & 315 & 385 & 325 \\
\hline 0128 & $\mathbf{3 6 5}$ & 305 & 370 & 335 \\
\hline Citrobacter freundii & $\mathbf{2 5 0}$ & 165 & 210 & $\mathbf{2 6 0}$ \\
\hline Aerobacter aerogenes & 700 & 500 & 750 & 680 \\
\hline
\end{tabular}

Colony diameters of six organisms were measured. Nine discrete colonies of each were measured on each of the four media, three colonies being measured on each of the three plates in the sector giving the smallest number of colonies greater than 2. Measurements were made by use of an eyepiece micrometer and a plate microscope, and were recorded as means of nine measurements. These mean values are shown in Table 3. From this table it will be seen that colonies of Salmonella typhimurium and of five pathogenic strains of Escherichia coli were larger on Teepol agar than on any of the three other media, including nutrient agar.

Table 3. Colony diameters of six organisms on Lemco agar, Teepol agar, and on two bile salt media

Sizes are expressed in millimetres and each is the mean of nine colonies measured.

$\begin{array}{lcccc}\text { Organism } & \begin{array}{c}\text { Lemco } \\ \text { agar }\end{array} & \begin{array}{c}\text { Taurocholate } \\ \text { MacConkey } \\ \text { agar }\end{array} & \begin{array}{c}\text { Tauro- } \\ \text { glycocholate } \\ \text { MacConkey } \\ \text { agar }\end{array} & \begin{array}{c}\text { Teepol } \\ \text { agar }\end{array} \\ \begin{array}{l}\text { Escherichia coli } \\ \text { O26 }\end{array} & & & & \\ \text { O55 } & 2 \cdot 0 & 1 \cdot 5 & 2 \cdot 1 & 2 \cdot 3 \\ \text { O111 } & 2 \cdot 0 & 1 \cdot 4 & 2 \cdot 1 & 2 \cdot 6 \\ \text { O119 } & 2 \cdot 1 & 1 \cdot 4 & 1 \cdot 9 & 2 \cdot 3 \\ \text { O128 } & 2 \cdot 1 & 1 \cdot 4 & 1 \cdot 9 & 2 \cdot 3 \\ \text { Salmonella typhimurium } & 1 \cdot 9 & 1 \cdot 6 & 1 \cdot 8 & 2 \cdot 2 \\ & 2 \cdot 1 & 1 \cdot 4 & 1 \cdot 5 & 2 \cdot 3\end{array}$


One or more strains of twelve serotypes each of Shigella and of Salmonella other than those listed in Table 3 were also found to grow freely on Teepol agar, and no strain of either was inhibited. Enterococci, micrococci and staphylococci did not grow.

A comparison was then made between Teepol agar and MacConkey agar in the isolation of serologically identifiable strains of Escherichia coli from rectal swabs taken from babies with gastro-enteritis. In every instance the swab was rubbed first on to the MacConkey agar plate and then on to the Teepol agar plate. In spite of this disadvantage a serologically identifiable strain of $E$. coli was isolated from the Teepol plate in every one of thirty-three instances in which it was also isolated from the MacConkey plate. In sixty-seven instances no isolation was made from either plate.

Teepol broth was tested in parallel with MacConkey broth for presumptive coli counts on 166 drinking waters and 162 sea waters. Ten ml. of drinking water were added to 5 tubes, $1.0 \mathrm{ml}$. to 5 tubes and $0.1 \mathrm{ml}$. to 5 tubes of each medium. Six tubes only were used for sea waters, $1.0 \mathrm{ml}$. being added to 2 tubes of each medium, $0.1 \mathrm{ml}$. to 2 tubes and $0.01 \mathrm{ml}$. to 2 tubes. Tubes showing acid and gas after $48 \mathrm{hr}$. at $37^{\circ}$ were subcultured to further tubes of the same medium at $44^{\circ}$ and read after $24 \mathrm{hr}$. Counts at $44^{\circ}$ were thus made on 112 drinking waters and 143 sea waters. All these counts are summarized in Tables 4 and 5 .

Table 4. Drinking waters

(a) Number of tubes set up

$\begin{array}{rc}\begin{array}{c}\text { Teepol } \\ \text { broth }\end{array} & \begin{array}{c}\text { MacConkey } \\ \text { broth }\end{array} \\ 2490 & 2490 \\ 1071 & 1014 \\ 43 \cdot 0 & 40 \cdot 7 \\ 539 & 498 \\ 21 \cdot 7 & 20 \cdot 0 \\ 50 \cdot 3 & 49 \cdot 1\end{array}$

Table 5. Sea waters

(a) Number of tubes set up

$\begin{array}{cc}\begin{array}{c}\text { Teepol } \\ \text { broth }\end{array} & \begin{array}{c}\text { MacConkey } \\ \text { broth }\end{array} \\ \mathbf{9 7 2} & \mathbf{9 7 2} \\ \mathbf{5 2 1} & \mathbf{5 2 4} \\ \mathbf{5 3 \cdot 6} & \mathbf{5 3 \cdot 9} \\ \mathbf{3 1 2} & \mathbf{3 1 9} \\ \mathbf{3 2 \cdot 1} & \mathbf{3 2 \cdot 8} \\ \mathbf{5 9 \cdot 9} & 60 \cdot 9\end{array}$

The mean probable numbers for the $37^{\circ}$ and $44^{\circ}$ counts on the drinking waters were interpolated by means of Table 4 of the Report (1939). $31 \cdot 3 \%$ of the $37^{\circ}$ counts were higher in Teepol, $43.4 \%$ were equal in the two media, and 25.3\% were higher in MacConkey broth. The corresponding percentages for the $44^{\circ}$ counts were $46 \cdot 4,33 \cdot 0$ and $20.5 \%$ respectively. 


\section{DISCUSSION}

In choosing ingredients for a differential medium for Bacillus coli communis and $B$. typhi abdominalis MacConkey adhered to the principle that these organisms should grow best in conditions most nearly identical with their normal habitat, the human intestine. The inclusion of bile salts in his medium was therefore a logical step which has been amply endorsed by the test of time. Teepol and other modern detergents had not been introduced in MacConkey's day, and even if they had been, MacConkey would have had no reason to suspect that they might be more useful in his medium than bile salts.

The tests on MacConkey agar and Teepol agar substantiated the earlier tests which led us to believe that Teepol had properties more favourable for use in culture media than those of sodium taurocholate and sodium tauro-glycocholate. Teepol agar was shown to support the growth of a wide range of intestinal pathogens which grow on MacConkey agar, to produce larger colonies, to suppress the swarming of Proteus species, and to be more selective against Gram-positive organisms.

Since May 1955 Teepol agar has been in routine use in our Laboratory in place of MacConkey agar which we formerly used for the isolation of Escherichia coli strains from faeces and for subculture of colony picks to sectors of plates. Colonies on Teepol agar do not readily go rough as on some batches of MacConkey agar and antigenically are at least equally suitable for slide-agglutination tests. Teepol withstands autoclaving at $10 \mathrm{lb}$. pressure for $10 \mathrm{~min}$., the method of sterilization we normally use; we have no reason to suppose that it would not withstand a longer period of sterilization at a higher temperature. In contrast with the batch variability of bile salts, we have found no corresponding batch variability in Teepol. Colour distinction between lactose and non-lactose fermenters on a mixed plate is less clear on Teepol agar than on MacConkey agar but opacity differences can be taken more into account. For primary isolation of non-lactose fermenting organisms both these media are far inferior to Leifson's medium (1935).

Tables 4 and 5 provide no evidence that Teepol broth is less suitable for counting than MacConkey broth. On the contrary, though all the instances in which the probable counts in MacConkey broth were higher than in Teepol broth can be attributed to sampling error, the converse is not the case. In each of two presumptive coli probable counts on drinking waters, 8 tubes more were positive with Teepol broth. The corresponding mean probable numbers given in the appropriate table of Report (1939) for these waters were as follows: Teepol broth 175 and $>1800$, MacConkey broth 8 and 50 respectively. The probability of the former 8-tube discrepancy occurring by chance at least once in 166 samples is greater than 0.05 , and this discrepancy might therefore have been due to chance alone. The value of $p$ for the latter discrepancy (which gave probable counts of $>1800$ and 50 respectively) occurring at least once in 166 samples is however less than 0.0375 . It is unlikely that this discrepancy was due to sampling error alone and it is a reasonable assumption that an organism in this water was more viable in Teepol broth than in 
MacConkey broth. It is also unlikely that the higher count was attributable to the presence in the water of a Gram-positive lactose-fermenting organism, since Teepol is more inhibitory than sodium taurocholate to Gram-positive organisms.

A detergent for use in culture media in place of bile salts should have the following properties; it should be chemically pure or of constant composition lacking bacteriologically undesirable impurities; it should not be inhibitory to Salmonella and Shigella species or to pathogenic strains of Escherichia coli; it should have relatively high selectivity and anti-swarming factors and it should be easily obtainable and cheap. The ease with which we found a detergent which fulfilled the above criteria suggests that there may well be other detergents equally suitable. It is therefore of interest that lauryl sulphate broth has been widely used in the United States for the presumptive test for coliform bacteria (Pederson \& Skinner, 1955).

The last but not least reason why we favour the use of Teepol is that of cost. A 1955 price-list by a well-known manufacturing chemist shows the price of $500 \mathrm{~g}$. of sodium taurocholate (sufficient for $100 \mathrm{l}$. of medium) as $\mathfrak{1 8}$. The corresponding cost of sodium tauro-glycocholate is given as £3. $0 s$. $6 \mathrm{~d}$. The cost of Teepol for $100 \mathrm{l}$. of medium is twopence!

Our thanks are due to Dr P. Armitage of the Medical Research Council's statistical unit for help and advice in the statistical calculations and to Shell Chemicals Ltd., for supplying samples of Teepol and olefine, and for permission to publish details concerning the constitution of Teepol.

\section{REFERENCES}

LEIFSON, E. (1935). New culture media based on sodium desoxycholate for the isolation of intestinal pathogens and for the enumeration of colon bacilli in milk and water. J. Path. Bact. 40, 581.

Lominski, I. \& Lendrum, A. C. (1942). The effect of surface-active agents on B. proteus. J. Path. Bact. 54, 421.

MacConkey, A. T. (1908). Bile salt media and their advantages in some bacteriological examinations. J. Hyg., Camb. 8, 322.

Miles, A. A. \& Misra, S. S. (1938). The estimation of the bactericidal power of the blood. J. Hyg., Camb. 38, 732.

Pederson, H. T. \& Skinner, C. E. (1955). A comparison of standard lactose broth with lauryl sulphate broth and with the Eijkman method for demonstrating fecal coliform bacteria. Appl. Microbiol. 3, 55 .

REPORT (1939). The bacteriological examination of water supplies. Rep. publ. Hlth med. Subj., Lond. no. 71. London: H.M. Stationery Office.

(Received 15 February 1956) 